\title{
Overprescribed Medications for US Adults: Four Major Examples
}

\author{
Daniel J. Safer
}

\begin{abstract}
To understand possible medication overprescribing, it would be important to know which classes are the most prescribed, for which indications, for what duration, and for which age groups. Among the 10 most frequently prescribed medication classes for US adults, four were evaluated for overprescribing, and systematically assessed in relation to their primary indication. The assessment included usage patterns, trends, age of recipients, treatment duration, and benefits versus adverse consequences. The findings in this selective review are supported by an extensive search of the medical literature. The four selected medication categories and their most common indication included opioids for chronic pain, proton pump inhibitors for indigestion, levothyroxine for subclinical hypothyroidism, and antidepressants for subsyndromal levels of depression. These medications, grouped by their most frequent indication along with polypharmacy, have experienced major prescription increases in recent years, particularly among older patients. Most concerning is that they have been frequently prescribed for extended periods, usually with inadequate evidence of benefit. High drug usage patterns can aid in quantifying overprescribing within polypharmacy by age group.
\end{abstract}

Keywords: Polypharmacy; Overprescribing; Opioids; Proton pump inhibitors; Levothyroxine; Antidepressants; Overmedicating

\section{Introduction}

Recent surveys in the USA show an increasing degree of prescribed medication treatment $[1,2]$. Many of the most commonly prescribed medications have resulted in measurable benefit, which include statin drugs and antihypertensives for cardiovascular disorders.

One would hope that all of the most commonly prescribed drugs and drug classes are the most biologically useful. However, this expectation merits a closer analysis. For example, opioids are a very common medication treatment, and strong

Manuscript submitted June 18, 2019, accepted July 15, 2019

Departments of Psychiatry and Pediatrics, Johns Hopkins University School of Medicine, Baltimore, MD 21287, USA. Email: dsafer@jhmi.edu

doi: https://doi.org/10.14740/jocmr3906 evidence indicates that they are prominently overprescribed. So I reviewed the medical literature to identify the ten most frequently prescribed drugs $[2,3]$. These include antihypertensive medications, statin drugs and insulin, drugs that are rarely associated with overprescribing $[4,5]$. But there were others listed in the most prescribed top ten whose benefit for their major indication requires careful assessment. These include proton pump inhibitors (PPIs) for gastric/esophageal symptoms, levothyroxine (LTX) for subclinical hypothyroidism $(\mathrm{SCH})$, opioids for relief of chronic pain, and antidepressants for subsyndromal levels of depression. So, I systematically explored the literature to ascertain if these four highly prescribed drug classes are routinely prescribed with benefit for their most common treatment indication.

Most studies on overprescribing emphasize the adverse consequences of high risk and inappropriate drug treatment for vulnerable adults. Such research usually centers on drug interactions with benzodiazepines, non-steroidal anti-inflammatory drugs (NSAIDs), and drugs that are anticholinergic [6, 7]. Their focus is not based on highly prescribed medications or on their inclusion within polypharmacy.

This critical review aims to elucidate to what degree the most common indications for PPIs, antidepressants, opioids, and LTX are medically beneficial, and how such prescribing adds to polypharmacy in older adults.

\section{Literature Search}

A literature review was performed using PubMed, Embase, Google, PsycINFO and Web of Science to describe the trends and recent treatment patterns of four of the ten most prescribed medication classes in the USA and of polypharmacy (taking five or more prescribed medications during the prior 30 days). Keywords searched were overprescribing, overmedication, $\mathrm{SCH}$, PPIs, opioids, antidepressants, LTX, and polypharmacy. For simplicity of presentation, LTX is included herein as a class. For the sake of brevity, this critical review focused only on major diagnostic and treatment evidence. It is a selective, not a comprehensive review. Prevalence surveys of US adults taking four very highly prescribed drug classes were assessed to note recent trends. Furthermore, the usage of these medications was identified by age group (e.g. 18 - 44, 45 - 64 and 65 and above) to determine if there were major differences in prescribed medication use with age. The literature survey on these four highly prescribed drugs was then further extended to focus on their relative benefits versus adverse drug events, 
Table 1. Percent of Medication Classes Used by US Adults Aged $\geq 20$ Years in 1999 - 2000 and 2011 - 2012 During the Prior 30 Days

\begin{tabular}{lll}
\hline Drug category & $\mathbf{1 9 9 9} \mathbf{- 2 0 0 0}$ & $\mathbf{2 0 1 1} \mathbf{- 2 0 1 2}$ \\
\hline SRI antidepressants & 4.3 & 8.5 \\
Levothyroxine & 4.6 & 6.0 \\
PPIs & 3.9 & 7.8 \\
Opioid analgesics & 3.8 & 5.7 \\
$\geq 5$ co-prescribed drugs & 8.2 & 15 \\
\hline
\end{tabular}

Modified from Kantor et al 2015 JAMA. SRI: serotonin reuptake inhibitors; PPI: proton pump inhibitors.

diagnostic specificity, duration of treatment, and off-label usage.

\section{Literature Review}

Medication prevalence data from large government sponsored surveys of US adults are presented in Tables 1 and $2[1,2]$. The survey findings on Table 1 reveal that the four selected medication classes were highly prescribed (6-9\% prevalence) to adults during the prior 30 days in 2011/2012. Also, their use had increased 30-100\% between 1999 - 2000 and 2011 - 2012 [1]. The national survey findings on Table 2 reveal that use of these medications increases with increasing age. Adults aged $\geq 65$ treated with these four drug classes or within polypharmacy increased two- to 10 -fold more than adults aged $18-44$ years. For U.S. adults aged 65 and over, $15-23 \%$ were taking at least one of these selected medication groups and $41 \%$ were taking five or more prescribed medications during the prior 30 days [3].

This review provides focused pharmacotherapy information on the major treatment indication of four, highly prescribed medication classes and on polypharmacy. The findings have implications for clinical practice. The relationship between examples of high medication usage, problematic maintenance, and overprescribing has not been discussed as such in the medical literature.

\section{Opioids}

Opioids to treat chronic pain represent the case of overprescribing of most concern. Opioids such as hydrocodone and Percocet ${ }^{\mathbb{B}}$ are useful for the short-term treatment of pain such as that occurring following a recent injury. Also, opioids are relatively safe for short-term use in appropriate oral doses. However, tolerance increasingly develops to the pain reduction effects of these drugs within weeks of use [8]. Consequently, raising the dose becomes necessary to maintain that benefit. Thus, when these drugs are administered at a stable dose over time, they become at best marginally effective to reduce pain $[9,10]$. However, increasing the dose and the duration of use creates a heightened risk of dependence and for some addiction [11]. Furthermore, the rapid cessation of maintained opioid treatment or a measurable dose reduction usually leads to
Table 2. Percent of Medication Classes Used in the Prior 30 Days by Age Group in a 2011 - 2014 Survey

\begin{tabular}{llll}
\hline \multirow{2}{*}{ Drug group } & \multicolumn{3}{c}{ Age groups (years) } \\
\cline { 2 - 4 } & $\mathbf{1 8 - 4 4}$ & $\mathbf{4 5 - 6 4}$ & Over 65 \\
\hline Antidepressants & 8.8 & 17.5 & 18.9 \\
Thyroid hormones & 2.2 & 8.1 & 15.5 \\
PPIs and $\mathrm{H}_{2}$ blockers & 3.8 & 14.1 & 23.2 \\
Opioids and other analgesics & 7.0 & 15.5 & 16.4 \\
$\geq 5$ co-prescribed drugs & 3.9 & 18.3 & 40.7 \\
\hline
\end{tabular}

Data taken from CDC Health, United States, 2016, Trend Tables 79 and 80. $\mathrm{H}_{2}$ : histamine $\mathrm{H}_{2}$ antagonists; PPIs: proton pump inhibitors.

untoward withdrawal symptoms.

Based on national survey data from 2015, it was estimated that 91.8 million US adults (38.7\%) used a prescribed opioid that year (mostly for pain), and an estimated 13.4 million of these adults misused or abused them [12]. Among adults prescribed opioids, $79 \%$ were long-term users ( $>90$ days of use) in 2013 - 2014 compared to $45 \%$ in 1999 - 2000 [13]. Opioid use for persistent pain peaks in the elderly [14]. Adverse effects from long-term opioid therapy include constipation (35\%), sleep disordered breathing (25\%), sexual dysfunction $(25-75 \%)$, sedation (15\%), depression/anxiety $(35 \%)$ and hyperalgesia [15]. In 2016, prescribed opioids accounted for 17,087 deaths in the USA [16].

\section{PPIs}

PPIs such as Prilosec ${ }^{\circledR}$ are useful for the treatment of gastric and duodenal ulcers, gastroesophageal reflux disorder (GERD), erosion of the esophageal lining, and a small number of specific gastrointestinal (GI) disorders. They successfully suppress acidity in the stomach [17].

PPIs are approved by the Food and Drug Administration (FDA) for 10 days for the treatment of Helicobacter pylori, up to 2 weeks for "heartburn", up to 8 weeks for GERD and for 2 - 6 months for ulcers $[18,19]$. Nonetheless, in a community survey, $60 \%$ remained on PPIs for over a year and $31 \%$ remained on them for 3 or more years [20]. Long-term use of PPIs increases the risk of fractures, gastric polyps, low magnesium levels in the blood, Clostridium difficile infections, and anemia [21]. Also, it is hard to discontinue maintained PPI use because $44-59 \%$ of patients experience symptomatic withdrawal (which occasionally can last for weeks) after the medication is discontinued $[22,23]$.

In practice, these drugs are most commonly prescribed by primary care physicians and for the treatment of indigestion [24]. Over $60 \%$ of patients taking PPIs do not have a licensed/ labeled indication for taking this medication or a documented GI diagnosis [24].

GI disorders such as GERD of course increase with age, but they are also increased in association with smoking, alcohol use, obesity, spicy food, and late meals [25]. So, life pattern changes to reduce GI symptoms can be very useful for treatment. 


\section{Levothyroxine (LTX)}

LTX is the standard replacement treatment for hypothyroidism, but it is a frequently inappropriate treatment for subclinical hypothyroidism $(\mathrm{SCH})[26,27] . \mathrm{SCH}$ is a diagnosis mainly based on thyroid stimulating hormone (TSH) blood levels mildly above the "normal" laboratory reference range, which is $0.5-4.5 \mathrm{mIU} / \mathrm{L}$. The SCH range for TSH is $4.5-10 \mathrm{mIU} / \mathrm{L}$ [28]. Although the TSH "normal" laboratory range $(0.5-4.5)$ represents a population average, it can be quite misleading because levels of TSH consistently and sizably increase with advancing age, particularly for adults over age 60 [29]. Also, TSH levels have been found to increase substantially in relation to region (about three fold), in iodine rich areas (two fold), race, in winter, at night, with morbid obesity, with exercise, during sleep deprivation, with numerous drugs, during pregnancy, and in disorders of the kidney and liver [30, 31]. Thus, it is no surprise that prevalence rates of $\mathrm{SCH}$ across studies in community populations range from $3 \%$ to $15 \%$ [32].

During follow-up assessments of patients with TSH levels from $5-10 \mathrm{mIU} / \mathrm{L}$ (in conjunction with a normal LTX level), $58-62 \%$ diagnosed with SCH reverted to customary age-expected TSH levels within $1-3$ years [33,34], although 2-3\%/ year had levels that then progressed into the hypothyroid range (over $10 \mathrm{mIU} / \mathrm{L}$ ) [35]. Monitoring elevated TSH levels over time is therefore necessary [33], but not a rush to treatment. Population outcome studies show that LTX treatment for $\mathrm{SCH}$ does not alter rates of mortality, depression, quality of life and cognitive function $[27,36]$.

Furthermore, treating SCH with LTX in the aged can inadvertently lead to overtreatment, increasing the risk of fractures and cardiac arrhythmias [37]. Abruptly stopping LTX can additionally be a problem because it takes many weeks for the body's feedback endocrine system to reactivate so as to deliver the appropriate amount of thyroxine [38]. LTX treatment adherence varies, but most of those in treatment for 6 or more months continue it for 4 or more years [39-41].

LTX is the most prescribed generic medication in the USA [3]. Like the other frequently prescribed drugs, it clearly has a legitimate use. However, the prevalence of clinically evident hypothyroidism in the USA is estimated to be $0.3-0.8 \%$, whereas the diagnosis of SCH in the USA averages $5 \%$ and is expanding [42]. Of late, LTX is often being prescribed more to treat older adults with complaints of fatigue, lethargy, weight gain, cognitive dysfunction, and despondency [43]. In the USA, women are prescribed LTX at a rate over twice that of men [3], even though their TSH levels are similar [44, 45].

\section{Antidepressant treatment}

Antidepressant treatment, particularly with serotonin reuptake inhibitors (SRIs), resulted in an additional symptomatic benefit of $25-30 \%$ compared to placebo treatment for adults diagnosed with major depressant disorder (MDD) who entered into short-term placebo-controlled clinical trials [46, 47]. Similar degrees of SRI short-term symptomatic benefit have been reported for persons with anxiety disorders [48]. Main- tenance findings from antidepressant trials are, however, far less supportive. In the sequenced treatment alternatives to relieve depression $(\mathrm{STAR} * \mathrm{D})$ project, a very large governmentsponsored, randomized clinical trial for adults diagnosed with $\operatorname{MDD}(\mathrm{n}=2,876)$, those in remission who entered into a 1-year antidepressant treatment follow-up averaged a strikingly high $(34-50 \%)$ rate of relapse during that maintenance period $[49$, $50]$.

The limitations of antidepressant maintenance are most evident in interview studies of adults $\geq 65$ years. In recent systematic surveys, only $15 \%$ of adults $\geq$ age 65 years who were taking antidepressants had met criteria for MDD during the prior year [51]. Furthermore in 2011 - 2014, a sizable 27\% of persons aged 12 and over who were taking an antidepressant had been doing so for ten years or more [52].

Although MDD was the only categorical diagnosis approved by the FDA for the treatment of unipolar depression, most depressed patients treated with antidepressants experience fewer than the required diagnostic number (five of nine for 2 or more weeks) of MDD symptoms [53-56]. These persons with subthreshold (subsyndromal) depressive symptomatology are, at best, marginal responders to antidepressants [55, 57-59].

Many antidepressants used for long-term treatment increase the risk of impaired sexual function, agitation, weight gain, type 2 diabetes, hypertension, and low bone density [59, 60]. Furthermore, at least $35 \%$ of persons who take antidepressants beyond 6 weeks experience unpleasant withdrawal symptoms when the drug is abruptly stopped or its dose is reduced $[61,62]$.

\section{Polypharmacy}

Polypharmacy (taking five or more prescribed medications in the prior month) is particularly common in the elderly. Adults aged $\geq 65$ years in the USA represented $13 \%$ of the population in 2010 [63], but received $39 \%$ of all prescriptions during that year [64]. Of course, adults aged $\geq 65$ have more chronic conditions. Specifically, $68 \%$ have two or more chronic conditions. These include hypertension (61\%), heart disease (32\%), arthritis (31\%), and diabetes (28\%) [65]. Such disorders and metabolic changes occurring with aging obviously account for some of the high medication rate in older adults. Nonetheless, polypharmacy adjusted for these confounds still leads to increased health care costs, more adverse drug events, detrimental drug interactions, increased hospital admissions, cognitive impairment, and more falls $[66,67]$. In one large study of adults over age 70 , increased odds of adverse drug reactions, when compared to matched patients taking three or fewer medications, were 3.6 for those taking $4-6$ medications, 4.6 for 7 - 9 medications, and 5.9 for 10 or more [68].

\section{Discussion}

This selective literature review supports the proposition that one particularly important place to look for medication over- 
prescribing is the most frequently used prescription drugs. As is apparent from this analysis of four highly prescribed medication classes, overprescribing is most common in older adults and in relation to long-term medication treatment. Hopefully, as a result of analyzing the overprescribing of specific highly prescribed drugs, by their major indication, pathways can be identified to better understand the dimensions of polypharmacy and thereby curtail its excesses.

\section{Acknowledgments}

None to declare.

\section{Financial Disclosure}

This research received no specific grant from any funding agency.

\section{Conflict of Interest}

The author does not have financial or non-financial conflict of interest.

\section{Informed Consent}

Not applicable.

\section{Author Contributions}

The manuscript was written entirely by DJS.

\section{Abbreviations}

GERD: gastroesophageal reflux disorder; PPI: proton pump inhibitor; FDA: Food and Drug Administration; NSAID: non-steroidal anti-inflammatory drug; LTX: levothyroxine; TSH: thyroid stimulating hormone; MDD: major depression disorder; SRI: serotonin reuptake inhibitor; $\mathrm{H}_{2}$ : histamine 2; STAR*D: sequenced treatment alternatives to relieve depression; SCH: subclinical hypothyroidism; GI: gastrointestinal

\section{References}

1. Kantor ED, Rehm CD, Haas JS, Chan AT, Giovannucci EL. Trends in prescription drug use among adults in the United States from 1999-2012. JAMA. 2015;314(17):18181831.

2. CDC Health, United States, 2016. Trend tables no.79 \& 80, pp. 293-297. https:/www.cdc.gov/nchs/data/hus/ hus/16.pdf.

3. IMS Institute Healthcare Informatics. Medicines use and spending in the U.S.2016. http://morningconsult.com/ wp-content/uploads/2016/04/IMS-Institute-US-Drugspending-2015.pdf.

4. Smith MA, Cox ED, Bartell JM. Overprescribing of lipid lowering agents. Qual Saf Health Care. 2006;15(4):251257.

5. Myers MG, Reeves RA, Oh PI, Joyner CD. Overtreatment of hypertension in the community? Am J Hypertens. 1996;9(5):419-425.

6. Beers $\mathrm{MH}$. Explicit criteria for determining potentially inappropriate medication use by the elderly. An update. Arch Intern Med. 1997;157(14):1531-1536.

7. Pugh MJ, Hanlon JT, Wang CP, Semla T, Burk M, Amuan ME, Lowery A, et al. Trends in use of high-risk medications for older veterans: 2004 to 2006. J Am Geriatr Soc. 2011;59(10):1891-1898.

8. Volkow N. Pain and psychiatry. Paper presented at the annual meeting of the American Psychiatric Association. San Diego CA, May 22, 2017.

9. Sanhu H, Underwood M, Furlan AD, Noyes J, Eldabe S. What interventions are effective to taper opioids in patients with chronic pain? BMJ. 2018;362:k2990.

10. Ashburn MA, Fleisher LA. Increasing evidence for the limited role of opioids to treat chronic noncancer pain. JAMA. 2018;320(23):2427-2428.

11. Volkow N, Benveniste H, McLellan AT. Use and misuse of opioids in chronic pain. Annu Rev Med. 2018;69:451465.

12. Han B, Compton WM, Blanco C, Crane E, Lee J, Jones CM. Prescription opioid use, misuse, and use disorders in U.S. adults: 2015 National Survey on Drug Use and Health. Ann Intern Med. 2017;167(5):293-301.

13. Mojtabai R. National trends in long-term use of prescription opioids. Pharmacoepidemiol Drug Saf. 2018;27(5):526-534.

14. Huang AR, Mallet L. Prescribing opioids in older people. Maturitas. 2013;74(2):123-129.

15. Baldini A, Von Korff M, Lin EH. A review of potential adverse effects of long-term opioid therapy: a practitioner's guide. Prim Care Companion CNS Disord. 2012;14(3):PCC.11mo01326.

16. Seth P, Scholl L, Rudd RA, Bacon S. Overdose deaths involving opioids, cocaine, and psychostimulants - United States, 2015-2016. MMWR Morb Mortal Wkly Rep. 2018;67(12):349-358.

17. Maes ML, Fixen DR, Linnebur SA. Adverse effects of proton-pump inhibitor use in older adults: a review of the evidence. Ther Adv Drug Saf. 2017;8(9):273-297.

18. Metz DC. Long-term use of proton-pump inhibitor therapy. Gastroenterol Hepatol (N Y). 2008;4(5):322-325.

19. Nexium FDA approved label. 12/2014. Assessed 4/19. https://www.accessdata.fda.gov/drugsafda_docs/label/20 14/022101s01402157s17021153s050lbl.pdf.

20. Pasina L, Urru SA, Mandelli S, Giua C, Minghetti P, Investigators $\mathrm{S}$. Evidence-based and unlicensed indications for proton pump inhibitors and patients' preferences for discontinuation: a pilot study in a sample of Italian community pharmacies. J Clin Pharm Ther. 2016;41(2):220223. 
21. Eusebi LH, Rabitti S, Artesiani ML, Gelli D, Montagnani M, Zagari RM, Bazzoli F. Proton pump inhibitors: Risks of long-term use. J Gastroenterol Hepatol. 2017;32(7):1295-1302.

22. Heidelbaugh JJ, Kim AH, Chang R, Walker PC. Overutilization of proton-pump inhibitors: what the clinician needs to know. Therap Adv Gastroenterol. 2012;5(4):219232.

23. Qvigstad G, Waldum H. Rebound hypersecretion after inhibition of gastric acid secretion. Basic Clin Pharmacol Toxicol. 2004;94(5):202-208.

24. Friedenberg FK, Hanlon A, Vanar V, Nehemia D, Mekapati J, Nelson DB, Richter JE. Trends in gastroesophageal reflux disease as measured by the National Ambulatory Medical Care Survey. Dig Dis Sci. 2010;55(7):19111917.

25. Mansour-Ghanaei F, Joukar F, Atshani SM, Chagharvand S, Souti F. The epidemiology of gastroesophageal reflux disease: a survey on the prevalence and the associated factors in a random sample of the general population in the Northern part of Iran. Int J Mol Epidemiol Genet. 2013;4(3):175-182.

26. Villar HC, Saconato H, Valente O, Atallah AN. Thyroid hormone replacement for subclinical hypothyroidism. Cochrane Database Syst Rev. 2007;(3):CD003419.

27. Stott DJ, Rodondi N, Kearney PM, Ford I, Westendorp RGJ, Mooijaart SP, Sattar N, et al. Thyroid hormone therapy for older adults with subclinical hypothyroidism. N Engl J Med. 2017;376(26):2534-2544.

28. Surks MI, Hollowell JG. Age-specific distribution of serum thyrotropin and antithyroid antibodies in the US population: implications for the prevalence of subclinical hypothyroidism. J Clin Endocrinol Metab. 2007;92(12):4575-4582.

29. Gharib H, Tuttle RM, Baskin HJ, Fish LH, Singer PA, McDermott MT. Subclinical thyroid dysfunction: a joint statement on management from the American Association of Clinical Endocrinologists, the American Thyroid Association, and the Endocrine Society. J Clin Endocrinol Metab. 2005;90(1):581-585; discussion 586-587.

30. Adlin V. Subclinical hypothyroidism: deciding when to treat. Am Fam Physician. 1998;57(4):776-780.

31. Kim YA, Park YJ. Prevalence and risk factors of subclinical thyroid disease. Endocrinol Metab (Seoul). 2014;29(1):20-29.

32. Bensenor IM, Olmos RD, Lotufo PA. Hypothyroidism in the elderly: diagnosis and management. Clin Interv Aging. 2012;7:97-111.

33. Kim TH, Kim KW, Ahn HY, Choi HS, Won H, Choi Y, Cho SW, et al. Effect of seasonal changes on the transition between subclinical hypothyroid and euthyroid status. J Clin Endocrinol Metab. 2013;98(8):3420-3429.

34. Meyerovitch J, Rotman-Pikielny P, Sherf M, Battat E, Levy Y, Surks MI. Serum thyrotropin measurements in the community: five-year follow-up in a large network of primary care physicians. Arch Intern Med. 2007;167(14):1533-1538.

35. Surks MI, Ortiz E, Daniels GH, Sawin CT, Col NF, Cobin RH, Franklyn JA, et al. Subclinical thyroid disease: sci- entific review and guidelines for diagnosis and management. JAMA. 2004;291(2):228-238.

36. Hennessey JV, Espaillat R. Diagnosis and management of subclinical hypothyroidism in elderly adults: a review of the literature. J Am Geriatr Soc. 2015;63(8):1663-1673.

37. Canaris GJ, Manowitz NR, Mayor G, Ridgway EC. The Colorado thyroid disease prevalence study. Arch Intern Med. 2000;160(4):526-534.

38. Krugman LG, Hershman JM, Chopra IJ, Levine GA, Pekary E, Geffner DL, Chua Teco GN. Patterns off recovery of the hypothalamic-pituitary-thyroid axis in patients taken of chronic thyroid therapy. J Clin Endocrinol Metab. 1975;41(1):70-80.

39. Li X, Wang Y, Guan Q, Zhao J, Gao L. The lipid-lowering effect of levothyroxine in patients with subclinical hypothyroidism: A systematic review and meta-analysis of randomized controlled trials. Clin Endocrinol (Oxf). 2017;87(1):1-9.

40. Somwaru LL, Rariy CM, Arnold AM, Cappola AR. The natural history of subclinical hypothyroidism in the elderly: the cardiovascular health study. J Clin Endocrinol Metab. 2012;97(6):1962-1969.

41. Mitchell AL, Hickey B, Hickey JL, Pearce SH. Trends in thyroid hormone prescribing and consumption in the UK. BMC Public Health. 2009;9:132.

42. Hollowell JG, Staehling NW, Flanders WD, Hannon WH, Gunter EW, Spencer CA, Braverman LE. Serum TSH, $\mathrm{T}(4)$, and thyroid antibodies in the United States population (1988 to 1994): National Health and Nutrition Examination Survey (NHANES III). J Clin Endocrinol Metab. 2002;87(2):489-499.

43. Taylor PN, Iqbal A, Minassian C, Sayers A, Draman MS, Greenwood R, Hamilton W, et al. Falling threshold for treatment of borderline elevated thyrotropin levels-balancing benefits and risks: evidence from a large community-based study. JAMA Intern Med. 2014;174(1):32-39.

44. Fontes R, Coeli CR, Aguiar F, Vaisman M. Reference interval of thyroid stimulating hormone and free thyroxine in a reference population over 60 years old and in very old subjects (over 80 years): comparison to young subjects. Thyroid Res. 2013;6(1):13.

45. Vadiveloo T, Donnan PT, Murphy MJ, Leese GP. Age- and gender-specific TSH reference intervals in people with no obvious thyroid disease in Tayside, Scotland: the Thyroid Epidemiology, Audit, and Research Study (TEARS). J Clin Endocrinol Metab. 2013;98(3):1147-1153.

46. Khan A, Brown WA. Antidepressants versus placebo in major depression: an overview. World Psychiatry. 2015;14(3):294-300.

47. Khan A, Schwartz K, Redding N, Kolts RL, Brown WA. Psychiatric diagnosis and clinical trial completion rates: analysis of the FDA SBA reports. Neuropsychopharmacology. 2007;32(11):2422-2430.

48. Williams T, Stein DJ, Ipser J. A systematic review of network meta-analyses for pharmacological treatment of common mental disorders. Evid Based Ment Health. 2018;21(1):7-11.

49. Pigott HE, Leventhal AM, Alter GS, Boren JJ. Efficacy and effectiveness of antidepressants: current status of re- 
search. Psychother Psychosom. 2010;79(5):267-279

50. Warden D, Rush AJ, Trivedi MH, Fava M, Wisniewski SR. The STAR*D Project results: a comprehensive review of findings. Curr Psychiatry Rep. 2007;9(6):449459.

51. Mojtabai R. Diagnosing depression in older adults in primary care. N Engl J Med. 2014;370(13):1180-1182.

52. Pratt LA, Brody DJ, Gu Q. Antidepressant use among persons age 12 and over; United States, 2011-2014. NCHS Data Brief No 283, Aug. 2017, p. 3.

53. Maust DT, Sirey JA, Kales HC. Antidepressant prescribing in primary care to older adults without major depression. Psychiatr Serv. 2017;68(5):449-455.

54. Mojtabai R. Clinician-identified depression in community settings: concordance with structured-interview diagnoses. Psychother Psychosom. 2013;82(3):161-169.

55. Olfson M, Blanco C, Marcus SC. Treatment of Adult Depression in the United States. JAMA Intern Med. 2016;176(10):1482-1491.

56. Rajakannan T, Safer DJ, Burcu M, Zito JM. National trends in psychiatric Not Otherwise Specified (NOS) diagnosis and medication use among adults in outpatient treatment. Psychiatr Serv. 2016;67(3):289-295.

57. Barbui C, Cipriani A, Patel V, Ayuso-Mateos JL, van Ommeren M. Efficacy of antidepressants and benzodiazepines in minor depression: systematic review and metaanalysis. Br J Psychiatry. 2011;198(1):11-16, sup 11.

58. Cameron IM, Reid IC, MacGillivray SA. Efficacy and tolerability of antidepressants for sub-threshold depression and for mild major depressive disorder. J Affect Disord. $2014 ; 166: 48-58$.

59. Hegerl U, Schonknecht P, Mergl R. Are antidepressants useful in the treatment of minor depression: a critical update of the current literature. Curr Opin Psychiatry. 2012;25(1):1-6.

60. Safer DJ. Raising the minimum effective dose of serotonin reuptake inhibitor antidepressants: adverse drug events. J Clin Psychopharmacol. 2016;36(5):483-491.

61. Fava GA, Gatti A, Belaise C, Guidi J, Offidani E. Withdrawal symptoms after selective serotonin reuptake inhibitor discontinuation: a systematic review. Psychother Psychosom. 2015;84(2):72-81.

62. Davies J, Read J. A systematic review into the incidence, severity and duration of antidepressant withdrawal effects: Are guidelines evidence-based? Addict Behav. 2019;97:111-121.

63. United States Census Bureau: Quick Facts United States. Population estimates (July 2016).

64. Charlesworth CJ, Smit E, Lee DS, Alramadhan F, Odden MC. Polypharmacy among adults aged 65 years and older in the United States: 1988-2010. J Gerontol A Biol Sci Med Sci. 2015;70(8):989-995.

65. CMS Chartbook 2012 ed. Chronic conditions among Medicare beneficiaries. https://www.cms.gov/ResearchStatistics-Data-and-Systems/Statistics-Trends-and-Reports/chronic-conditions/downloads/2012Chartbook.pdf.

66. Maher RL, Hanlon J, Hajjar ER. Clinical consequences of polypharmacy in elderly. Expert Opin Drug Saf. 2014;13(1):57-65.

67. Oscanoa TJ, Lizaraso F, Carvajal A. Hospital admissions due to adverse drug reactions in the elderly. A meta-analysis. Eur J Clin Pharmacol. 2017;73(6):759-770.

68. Laroche ML, Charmes JP, Nouaille Y, Picard N, Merle L. Is inappropriate medication use a major cause of adverse drug reactions in the elderly? Br J Clin Pharmacol. 2007;63(2):177-186. 